\title{
MODERN TECHNOLOGIES OF ACQUISITION OF FUNDS OF CITIZENS BY THE FINANCIAL PYRAMID
}

\author{
Serhii Cherniavskyi ${ }^{1}$, Andriy Zapototskyi ${ }^{2}$, Anton Syzonenko ${ }^{3}$
}

\begin{abstract}
The purpose of the article is to study the criminalistics of the use of the most common technologies of acquisition of funds of citizens, done by the way of the financial pyramid. The subject of the study is the content of criminal technology of fraudulent way of the financial pyramid. Methodology. The research is based on the use of general scientific and special-scientific methods and methods of scientific knowledge. The historical-legal method allowed determining the genesis of the concepts of "technology of criminal activity" and "financial pyramid", as well as the formation of scientific and theoretical views on problems and methods of combating them. The comparative legal method was used to compare the doctrinal approaches of legislative regulation to counteract fraud committed by the method of the financial pyramid. The system-structural method contributed to the awareness of the technologies of preparing, committing, and concealing the fraud. The methods of grouping and classification were the basis for the author's approach to the differentiation of technologies for the acquisition of funds of citizens, depending on the organizational and legal form, under the cover of which a financial pyramid was created. The statistical method is used in the analysis of investigative and judicial practice for ten years. The results of the study showed that the method of financial pyramid used for committing fraud is fully structured and includes criminal technologies for preparing, committing, and concealing the fraud. The combination of separate technologies in the mechanism of the crime is aimed at masking the active phase of criminal activity under civil-law relations, which complicates the timely detection of the signs of the crime both by the victim and by law enforcement agencies. Practical implications. The research carried out the typing of fraudulent techniques using the financial pyramid method, which is the basis for developing and improving methods of disclosure and investigation of crimes. Value/ originality. On the basis of the proposed author's approach to the differentiation of technologies of criminal activity, it is possible to predict the emergence of the new ways of committing fraud in the financial sector.
\end{abstract}

Key words: fraud, financial pyramid, technology of criminal activity, way of committing a crime.

JEL Classification: F38, P34

\section{Problem statement and degree of its scientific development}

Currently, the schemes for the acquisition of funds of citizens by the way of the financial pyramid, disclosed by law enforcement agencies of Ukraine, cause special concern of their scale. During 2006-2016, according to the Ministry of Internal Affairs and the National Police, in proceedings of investigators, there were almost 300 criminal cases (proceedings) on crimes in this category, in which more than 200 thousand citizens were found to be victims. The resulting aggregate losses amounted to over 2 billion UAH, of which the victim was compensated no more than a quarter (An analytical note on the state and structure of crime in Ukraine for 2008-2017). All these ways of illegal acquisition of property of citizens distinguish the high level of professionalism of criminals, masking their activities with the help of well-known world brands and economic entities with offshore status, use of modern information technologies, special methods of psychological influence, as well as corruption support from interested officials of all levels.

The problems of proving fraud committed by the method of a financial pyramid are primarily due to the fact that the organizations under the protection of which such a pseudo-organization has been created are usually officially registered and conclude civil-law agreements with victims, and signs of acquisition of property are, as a rule, much later the onset of criminal consequences. Moreover, modern payment systems, primarily different schemes of "on-line" payments, create conditions for obtaining and laundering of proceeds from crime. As a result, property rights and interests of Ukrainian citizens may be affected, as well as the preconditions for

\footnotetext{
Corresponding author:

${ }^{1}$ National Academy of Internal Affairs, Ukraine.

${ }^{2}$ National Academy of Internal Affairs, Ukraine.

${ }^{3}$ National Academy of Internal Affairs, Ukraine.
} 
increasing tension in society (Explanatory note to the draft Resolution of the Verkhovna Rada of Ukraine).

Different aspects of counteraction to fraud, which were done by using financial instruments and psychological effects, were investigated in their works by A. F. Volobuiev, V. I. Haienko, S. V. Holovkin, Ye. V. Dekhtiarov, S. M. Kniazev, O. V. Kravchenko, V. V. Lysenko, Y. M. Meslovskyi, O. L. Musienko, T. V. Okhrimchuk, T. A. Pazynych, I. M. Popova, T. L. Tsenova, V. Yu. Shepitko, and others.

At the same time, in the scientific literature, the peculiarities of the technology of fraudulent actions concerning the acquisition of funds of citizens in the form of a financial pyramid are not disclosed. Therefore, the purpose of this article is to highlight the characteristics of the technology of acquisition of funds of citizens in the way of the financial pyramid in modern conditions.

\section{Presenting the main material}

Scientists offer different approaches to the definition of a financial pyramid, which collectively form the three main concepts: economic, mathematical, and legal (Cherniavskyi, 2010).

Typically, financial pyramids are recorded as business entities (financial institutions) that attract funds for a particular project. If the real profitability of the project is lower than the income promised to investors or none at all, then a part of the means of new investors is directed to the payment of dividends to the previous one. The logical result of this situation is the inevitable financial failure of the project and the damage of the last investors. Practice shows that after the collapse of the pyramid, no more than $10-15 \%$ of attracted funds can return. After all, the funds collected by the organizers of the pyramid do not direct the acquisition of liquid assets but immediately used for payments to the first participants, advertising, and personal enrichment. The longer the pyramid functions, the less is the percentage of possible returns in case of its liquidation (Kardava, 2002).

Financial pyramid as a method of fraud should be distinguished from quite legitimate financial activity on a number of grounds, which indicate the fraud of investors (depositors), which are the basis of the "pyramid":

1) the main task of the organizers of the financial pyramid is the attraction of new investors, whose participation is provided by new project revenues, that is, the amount of funds attracted from investors exceeds the amount of profit value that provides a certain investment project;

2 ) the presence of active advertising in the media, which promises to pay dividends at an interest rate, the size of which significantly exceeds the average market;

3 ) the use of technically equipped offices in prestigious areas of cities, holding pathetic presentations, a wellestablished system of work with clients;
4) the opaque scope of activity, that is, participants in the financial pyramid cannot verify the nature of the investment project and the direction of the attracted funds;

5) the use of several companies that hide the financial pyramid, multiple reorganization, change of organizational forms, legal address, offshore registration of companies;

6) creation of a convincing legend of investments, the illusion of deep analysis and scientific substantiation of investment policy, use of cover documents, in particular, regarding the support of the project by state authorities, powerful financial institutions;

7) payment of dividends and return of borrowed funds at the initial stage of the activity of the financial pyramid (at the stage of "promotion") in order to create confidence in the reliability of the project to investors.

Thus, the financial pyramid should be considered, firstly, as a method of fraud that ensures the realization of the fraudulent intent of fraudsters and, at the same time, as a tool for earning profits by professional managers through the attraction of investors' funds. The fundamental distinction between a financial pyramid as a criminal activity and a real business project is the reality of the commitments undertaken by the organizers to investors, as well as the source of dividend payments.

In science, the technology of criminal activity reflects a set of actions (operations) of the subject to prepare, commit, and conceal the crime in their dynamics and sequences occurring in specific conditions of place and time (Cherniavsky, Kniazev, Tatarov, etc. (2013).

The features of these elements affect the character and location of traces and signs of crime. The financial pyramid as a method of fraud includes a number of technologies of criminal activity aimed at preparing, committing, and concealing the illegal possession of someone else's property by deception and abuse of trust. The study of judicial practice shows that usually at the stage of creating a financial pyramid, criminals use the following technologies:

1) the creation of economic entities or acquiring rights to management established by economic entities;

2) obtaining detailed information on the procedure for conducting individual financial transactions and conducting reconnaissance activities by fraudsters;

3 ) the use of organizational and technical measures to cover criminal activity;

4) attracting new participants to increase the volume of the financial pyramid;

5) application of psychological influence to impacted victims;

6) additional measures for masking criminal activity.

Consider these technologies in more detail.

1. Creation of business entities or acquiring rights to management established by economic entities at the stage of preparation for committing fraud is aimed at: using their organizational and legal status to simulate 
legal financial and economic activity; legalization of a criminal group in a market environment of a certain region (country, city); access to economic and financial instruments (opening bank accounts, concluding commercial agreements, leasing office space, etc.).

Typically, fictitious business entities are used to create a financial pyramid, they are registered on the front men, persons who have lost their passports, are in places of deprivation of liberty, mentally ill or those who have left for permanent residence abroad.

So, for the purpose of realization of the criminal intent, the organizers of the financial pyramid were registered with the NGO "Fund K.." The official founder of this organization has become a citizen of retirement age A., who never worked and agreed to give his personal data for the reward. Wronging with the intentions of the organizers, immediately after registration A. transferred to unidentified persons received registration documents, seal and facsimile of his signature (Cherniavskyi, Vozniuk, Zapototskyi, etc. (2016).

In the name of such organizations, for the most part, lay the idea of quickly obtaining extra profits ("Your chance"; "Fast money"); use of advanced business technologies and affiliation with world innovations ("Business Capital", "Elite-Centre"); patronage of the mythical forces ("Mercury"; "Hermes"); international relations ("Golden Circle International"; "Global System of Trainings"); noble motives to help lowincome groups of the population ("Averter"). In some cases, in the name of these organizations, in violation of the current legislation, there is a reference to affiliation with financial institutions, as well as well-known foreign companies.

2. Getting detailed information on the procedure for conducting certain financial transactions, keeping proper records, the situation of the financial market, studying the possibilities and effectiveness of control by law enforcement agencies, the rules for drawing up documents for conducting financial transactions, the order of their filling and passing from the executor to the addressee, the order of application of search and information systems by fraudsters. This information organizers and members of a group of scammers who create a financial pyramid, use it from personal experience, as well as acquire by means of observations, consultations with specialists, studying of special literature. Having enough information, fraudsters in many cases make a model of committing a crime. Subsequently, this model is embodied in plans, schemes, calculations, charts, etc. At the same time, the role and place of each participant in the future criminal scheme are modelled (planned).

For example, during the six months, P. was searching for employees for the newly created LLC "Bank Ukraine" as financial advisers. For the purpose of carrying out the criminal activity, three people - experts of the financial market who carried out seminars with participants of the criminal group, which talked about the latest stock and trades activities, as well as prospects for future activities of the company, were involved. During the seminars, members of the criminal group were trained to work with clients while preparing them for work as financial advisers (according to the Main Investigation Department of the Ministry of Internal Affairs of Ukraine, 2011).

The use of reconnaissance activities is aimed at finding and establishing contacts with the heads of business entities, banks, and other financial institutions in order to create an appropriate image, in particular, through advertising in mass media (Internet), with representatives of control and law enforcement agencies to ensure corruption coverage of their activities with persons who have special knowledge of certain technological processes of financial transactions, in particular, in computer networks, flow of documents to use them as support consultants.

3. Organizational and technical measures for the coverage of criminal activities are aimed at leasing offices, hiring staff, providing business attributes, distributing wide-ranging advertising to create a false representation of citizens about conditions of the participation in the organization, the production of necessary documents (forms, standard contracts, business cards, certificates, licenses), the purchase of the necessary equipment, computer and office equipment, and other measures for the technical maintenance of actions at all stages of the commission a crime.

4. Involvement of new participants in the financial pyramid is realized, as a rule, through meetings (workshops, trainings, lectures) conducted by organizers of fraud with potential victims (private investors) on the basis of leased premises (assembly rooms of state institutions, cinemas, hotels, etc.). The typical scheme of these meetings consists of several stages:

- participants of the gathering are collected by distributing on behalf of the organization of invitations (guests are often invited together with "partners", whose role is played by members of the criminal group, with the aim of psychological pressure from their side to unprepared citizens);

- the organizer personally meets the invited guests and invites them to get acquainted with the organization's colour brochures illustrating its "achievements" and authority in the respective circles;

- for a public performance, the organizer, as a rule, goes out to the improvised scene for music and, for example, appears to be the marketing director of a virtually nonexistent internationally renowned company (for more convincing, he gives the floor to his accomplices who act as "wealthy" through participation in the organization); - with reference to the rules of the organization, the organizer states that he has the right to raise funds and to distribute them for the benefit of the members of the organization; 
- during the meeting, participants receive forms of confidential agreements with the organization, applications, and other documents that create the illusion of involvement in a serious business project;

- among the sources of income from participation in the organization they promise to victims, firstly, the opportunity to obtain "crazy interest" (usually from 40 to $100 \%$ ) through the participation in financial, trading, and stock markets; secondly, to earn "big money" as a result of their ability to invest in a "serious innovation project", usually abroad (offer to use for a quick enrichment initially small amounts of funds, in particular, borrowed);

- at the end of the workshop with novices, personal conversations are conducted, during which, in view of a particular psychological state of the person, the organizers convince the latter of the veracity of their words;

- numerous demands for the return of savings correspond to the fact that this is not foreseen by the "club rules" but the only way to return the money is to attract as many new participants as possible.

So, in preparation for committing crimes in order to mislead the public, F. held seminars at the business centre in Kyiv, where they told invited citizens about the utility of investing money in instruments of the financial markets of the world, in particular, the international company, he is the representative of the territory of Ukraine and Eastern Europe. At the workshops, F. told citizens about the profits that can be obtained from investing money into financial market instruments. During the preparation for committing crimes, F. and other members of the criminal group developed promotional leaflets for further distribution to future clients of the company. To the indicated booklets on the instructions, F. introduced false information about the history and activities of the non-existing international group of companies, positioned in booklets as a worldrenowned and reliable asset management company, represented in 33 countries of the world. At the same time, citizens were encouraged to invest money in accordance with the investment programs of the company that provided the profits (up to 5\% per month and 54\% per annum). Financial advisers of the company, not being aware of the criminal intentions of F., persuaded the clients in the profitability of investing funds (according to the materials of the Main Investigation Department of the National Police of Ukraine, 2016).

5. A characteristic feature of the activities of financial pyramids is the involvement of new participants using psychological influences or methods of neuro-linguistic programming (NLP). The basis of NLP is the use of so-called "anchors" - shaped stimuli that cause a certain reaction. NLP receptions are increasingly used in advertising, management, counselling, training for advanced training, etc. to achieve more effective communication, individual development, and accelerating the development of certain skills. Getting into the club, the person does not even assume that it is imperceptibly influenced by psychological pressure and hypnosis.

Hidden instructions and commands, the feature of which is the incentive to make unconscious decisions, are built to the structure of the expressions of "moderators". The lyrics contain no contradictions and controversies in the arguments; the neutrality of the material presentation is maintained. The examples presented did not affect any of the present, so the listeners did not have any doubts or negative associations. Thanks to these techniques in the classroom, there was a sense of agreement, sympathy for the leader, and his messages were evaluated as correct and logical.

At the final stage of such a "workshop", there are so-called "individual interviews", combined with additional psychological influence, aimed at ultimately suppressing the will of the victims for their predilection to the transfer of money to fraudsters. On the stage in the centre of the hall lay tables, for which all the same "managers" sat down. Central illumination is usually turned off. The entire "interview" process is accompanied by loud music. Creating convenient conditions for communication, "managers", follow the instructions of the organizers, persuading citizens to join the "company", demanding to immediately give consent and to confirm their words to make appropriate monetary payments.

In several proceedings, the experts analysed the musical accompaniment of "workshop" to the existing sound recordings of musical compositions, testimonies of victims and witnesses. Found that there was a targeted use of specially selected rhythms that performed a polyfunctional role in the mechanism of psychological impact on victims. The peculiarities of musical compositions, their rhythm and rapid pace (120-140 beats per minute) destabilized the emotional state of the victims, deprived them of their ability to concentrate attention, caused the inhibition of mental activity, the weakening of logical thinking, which in the decision-making situation led to surface judgments, hasty actions, dependence on external stimuli.

6. There is now a clear tendency to mask financial pyramids through three outwardly legal areas of work. The first direction is the creation of "elite clubs", whose members expect to receive high revenues from joint activities. The most striking example of the creation of such clubs is the network created by the organizers of financial pyramids in a number of our cases. It was based on elite closed clubs, whose members were bound to have an extremely respectable appearance, to pay high contributions (at least $\$ 1,000$ ) for the right to enter and visit the club. Clubs were extremely cautious in choosing future members, given their financial status, suggestiveness, willingness to believe unreliable statements, etc., and immediately warned novices about 
the need for the quickest involvement of new entrants, otherwise, dividends would not be paid. At the same time, members of the club did not officially buy any shares or bonds but made contributions as donations of some amount of one private person - to another.

The second direction is the division of the "pyramid" into several specialized divisions, most of which deal with outwardly legal activities and is an officially recognized source of profit. An example of this structure is the activities of the Club Foundation K., which, in place of one company, created a whole system of organizations (18 business entities), engaged in investments, financial transactions, and purely trading activities in Ukraine and abroad.

An important feature of modern financial pyramids is their strong religious slant, in particular, in the field of eastern mysticism. The heads of "affiliates" and the most responsible officials in religious organizations that are used to create a financial pyramid were appointed only from the closest students of the founder, who formally only engaged in spiritual education. However, the financial basis of these organizations is the usual pyramid of payment of bonuses to participants who joined earlier due to the contributions of beginners.

Realization of the analysed technologies of misappropriation funds of citizens in the way of the financial pyramid takes place taking into account the organizational and legal form, under the cover of which the financial pyramid was created, in particular:

1) in the activities of credit unions;

2 ) in the field of investment activity (in the form of providing services or investing in a profitable project);
3) under cover of insurance organizations;

4) under the guise of attracting funds from citizens to construction;

5) through the tools of providing financial services on the Internet.

The first two groups are the so-called "classical pyramids", whose organizers are covered only by external attributes and promises of profits in the future. The last three types of the financial pyramid are used economic substantiation of investments (in construction, insurance, in the virtual financial markets) as masking of criminal acts.

\section{Conclusions}

We described the modern criminal technologies of acquisition of funds of citizens in the form of a financial pyramid and the distinctive features (characteristic features) inherent in various types of "financial pyramids". The method of financial pyramid used for committing fraud is full-fledged and includes criminal technologies for preparing, committing, and concealing of someone else's property. The combination of these technologies in the mechanism of the crime is aimed at masking the active phase of criminal activity under civillaw relations, which complicates the timely detection of the signs of the crime both by the victim and law enforcement agencies. The scientific generalization and typification of fraudulent techniques in the form of a financial pyramid is the basis for developing and refining methods for the disclosure and investigation of these crimes, and for forecasting the emergence of new ways of criminal activity.

\section{References:}

An analytical note on the state and structure of crime in Ukraine for 2008-2017. Retrieved from: http://mvs.gov.ua Explanatory note to the draft Resolution of the Verkhovna Rada of Ukraine "On holding parliamentary hearings on the topic: "Problems of legislative regulation of the activity of modern types of financial pyramids based on the use of information technologies and systems of direct sales". Retrieved from: http://www.zakon1.rada.gov.ua

Cherniavskyi, S. S. (2010). Financial fraud: methodological principles of investigation: [monograph]. K., 624 p.

Kardava, D. V. (2002). Network Marketing - Pyramid? Scam? Or ... The system of distribution of goods and services. M., pp. 128-136.

Cherniavsky, S., Kniazev, S., Tatarov, O. and others (2013). Investigation of fraud committed by the method of a financial pyramid [Text]: manual. K., 138 p.

Cherniavskyi, S. S., Vozniuk, A. A., Zapototskyi, A. P., etc. (2016). Investigation of criminal offenses related to fictitious business and the activities of "conversion centers" [text]. K.: Nat. acad. internal affairs, 92 p. 